\title{
Cough Reflex Sensitivity in Adolescents with Diabetic Autonomic NEUROPATHY
}

\author{
M. Ciljakova, J. Vojtkova, P. Durdik, T. Turcan, M. Petrikova, Z. Michnova, P. Banovcin \\ Clinic of Children and Adolescents, Jessenius Faculty of Medicine, Comenius University, Martin, Slovakia
}

\begin{abstract}
Objective: Diabetic autonomic neuropathy (DAN) is one of the chronic complications of diabetes mellitus which can involve one or more organ systems. DAN without apparent symptoms is more often in childhood and adolescence. While heart rate variability (HRV) and Ewing's battery of cardiovascular tests are regarded as a gold standard for the diagnosis of DAN, the examination of cough reflex sensitivity (CRS) is another possibility. The aim of this study was to compare HRV and CRS in children with diabetes mellitus.

Material and Methods: Sixty one patients (37 girls, 24 boys) aged 15-19 suffering from diabetes mellitus type 1 completed the study. Based on HRV, patients were divided into 2 groups - with DAN ( $\mathrm{n}=25)$ and without DAN ( $n=32), 4$ patients were excluded because of ambiguous results. CRS was studied in each patient by inhalation of gradually increasing concentration of capsaicin.

Results: Subjects with DAN required a significantly higher concentration of capsaicin needed to evoke 2 coughs (median $625 \mu \mathrm{mol} / \mathrm{l}$, IQR $68.4-625.0 \mu \mathrm{mol} / 1$ vs. median $29.3 \mu \mathrm{mol} / 1$, IQR 9.8-156.3 $\mu \mathrm{mol} / 1$, $\mathrm{P}<0.001$ ) and 5 coughs (median $2500.0 \mu \mathrm{mol} / \mathrm{l}$, IQR 1250.0-2500.0 $\mu \mathrm{mol} / 1$ vs. median $312.5 \mu \mathrm{mol} / 1$, IQR 117.2-625.0 $\mu \mathrm{mol} / 1, \mathrm{P}<0.001)$ compared with those without DAN. Moreover, a strong negative correlation between HRV and CRS was established.

Conclusion: Diabetes mellitus lowers the cough response. Cough reflex sensitivity appears to be another sensitive method for the evaluation of DAN in diabetes.
\end{abstract}

Key words: diabetic autonomic neuropathy, heart rate variability, cough reflex sensitivity

\section{INTRODUCTION}

Diabetic autonomic neuropathy (DAN) is one of the most common chronic complications of diabetes mellitus (DM); however, it is usually underestimated. DM can appear as clinically evident with symptoms of sensory or autonomic nervous systems, but may also be present subclinically without any apparent symptoms.

While clinically evident DAN comes to sight usually after long-lasting DM, subclinical DAN can occur within 1-2 years from the diagnosis of DM [1]. Heart rate variability (HRV) and Ewing's cardiovascular tests (resting breathing, deep breathing, and orthostatic exam) and spectral analysis are regarded as gold standards in the diagnosis of DAN [2].

Changes in respiratory system in diabetic patients are caused mainly by microangiopathy of pulmonary capillaries with thickened basal membrane, changes in collagen, and by autonomic neuropathy. The consequences are the following: alterations in function and structure of the respiratory system - decreased pulmonary volumes, decreased diffuse lung capacity, and decreases in compliance, basal bronchial tone, and sensitivity to cough [3]. Clinically, the most severe pulmonary complications are infections of the lower respiratory tract, which can be fatal in immunodeficient patients.

The vagus nerve, which is one of the first nerves, damaged in DM, apart from other functions, mediate the cough reflex. Therefore, in the present study, we presumed that changes in cough reflex sensitivity (CRS) might help detect and assess the severity of DAN, in that the lower CRS, the greater dysfunction of the vagi and more severe DAN. We addressed the issue by comparing HRV and CRS in children with diabetes mellitus type I.

\section{Material AND Methods}

The study was approved by the local Ethics Committee of the Jessenius Faculty of Medicine in Martin, Slovakia. Patients were enrolled in the study based on these criteria: DM type I, age 15-19 years, and written informed consent. Diabetic patients with disorders of nervous system, chronic respiratory and cardiovascular diseases were excluded from the study. Subjects with ketoacidosis or acute respiratory infection were included in the study, at least 4 weeks after recovery. HRV and CRS were studied in each patient.

\section{HEART RATE VARIABILITY}

HRV (Ewing's tests, spectral analysis) was examined using the Varia Pulse TF4 system (Sima Media, Olomouc, Czech Republic) following standard conditions. After resting in the supine position, children were instructed to breathe deeply at a frequency of $6 \mathrm{cy}-$ cles/min. The result of deep breathing test was expressed as I/E and CVrr parameters. Measured para- 
meters were compared with reference values for appropriate age and sex [4].

\section{Cough Reflex Sensitivity}

CRS was studied by inhalation of increasing capsaicin concentration. A capsaicin solution was prepared ex tempore in gradually increasing concentrations of capsaicin. Each patient inhaled aerosol of control solution $(0.9 \%$ saline), followed by inhalation of 12 capsaicin aerosol concentrations in doubling doses (0.61, $1.22,2.44,4.88,9.76,19.53,39.06,78.12,156.25$, $312.5,625$ and $1250 \mu \mathrm{mol} / \mathrm{l}$ ) at $1 \mathrm{~min}$ intervals. The aerosol of capsaicin was prepared by the jet nebulizer (Koko Digi-Doser-Spirometer, nSpire Health Inc, Louisville, USA). The nebulization was guided by computer within $400 \mathrm{~ms}$ and subjects were supposed to breathe through the mouth with the pressed nose. CRS was defined using two parameters: the lowest concentration of capsaicin needed to evoke 2 (C2 parameter) or 5 coughs (C5 parameter) [5]. If the subject could not evoke 5 coughs by inhalation of the highest concentration, $2500 \mu \mathrm{mol} / 1$ was considered as the C5 parameter.

\section{Diagnosis of Diabetic Neuropathy}

Diabetic neuropathy was assessed on the basis of 2 parameters (CVrr, I/E) in deep breathing test. CVrr and $\mathrm{I} / \mathrm{E}$ parameters are regarded to be the most sensitive for the evaluation of early stage of DAN. Patients with both parameters below the $10^{\text {th }}$ percentile were regarded to have diabetic autonomic neuropathy (DAN+), and those with CVrr and I/E above the $10^{\text {th }}$ percentile were supposed to be without neuropathy (DAN-). CRS parameters were compared between these two groups of patients; moreover, a correlation between CRS and HRV parameters was measured.

\section{STATISTICAL EvaluATION}

The results were analyzed by the SYSTAT statistical program (version 11). Since the observed parameters were distributed non-parametrically, they were expressed as median with interquartile range $(I Q R)$ - the $25^{\text {th }}$ and the $75^{\text {th }}$ percentile. To assess significant difference between subgroups, Mann Whitney U-test was used. $\mathrm{P}<0.05$ was considered to be statistically significant. Spearman's correlation coefficient was used to establish the relationship between non-parametric variables. Correlation coefficients of $0.3-0.5$ were regarded as moderate, $0.5-0.7$ as strong, $0.7-0.9$ as very strong, and $0.9-1.0$ as a nearly ideal correlation.
Table 1. Characteristics of all patients $(\mathrm{n}=61)$.

\begin{tabular}{lc}
\hline Parameter & Median (IQR 25-75) \\
Age (years) & 17 (IQR 15-18) \\
Onset of DM (years) & 10 (IQR 6-13) \\
Duration of DM (years) & 5 (IQR 3-10) \\
BMI (kg/m²) & 20.8 (IQR 19.2-23.3) \\
HbA1c $\%$ ) & 10.3 (IQR 9.2-12.5) \\
Cholesterol (mmol/l) & 4.7 (IQR 4.2-5.5) \\
Triglycerides (mmol/l) & 1.0 (IQR 0.8-1.5) \\
Microalbuminuria (mg/day) & 9.8 (IQR 2.0-20.7) \\
\hline
\end{tabular}

\section{RESULTS}

Sixty one patients (37 girls, 24 boys) aged 15-19 with DM type 1 completed the study. The median age of children was 17 years, interquartile range (IQR) 15-18 years. Duration of DM was 5 years (median, IQR 310 ); onset of DM was at the age of 10 years (median, IQR 6-13). The monitored parameters of all patients are presented in the Table 1.

According to HRV (CVrr, I/E parameters), subjects were divided into subgroups. Twenty five patients (41\%) had both parameters below the $10^{\text {th }}$ percentile, these were supposed to have diabetic neuropathy (DAN+). HRV parameters of 32 subjects were within the normal range (subgroup DAN-). Another four patients had only one of these parameters below the $10^{\text {th }}$ percentile, and these results were considered ambiguous and the patients excluded from further analysis. CRS parameters (C2 and C5) were compared between groups DAN+ and DAN- (Table 2).

Comparing the two subgroups, the DAN+ patients required a significantly higher concentration of capsaicin needed to evoke 2 coughs than those the DANpatients (median $625 \mu \mathrm{mol} / \mathrm{l}$, IQR $68.4-625.0 \mu \mathrm{mol} / 1$ vs. median 29.3, IQR 9.8-156.3 $\mu \mathrm{mol} / 1$, respectively; $\mathrm{P}<0.001$ ) (Fig. 1). Similarly, the $\mathrm{DAN}+$ subgroup required a significantly higher concentration of capsaicin needed to evoke 5 coughs (median 2500.0 $\mu \mathrm{mol} / \mathrm{l}$, IQR $1250.0-2500.0 \mu \mathrm{mol} / 1$ in DAN+ vs. median $312.5 \mu \mathrm{mol} / 1$, IQR 117.2-625.0 $\mu \mathrm{mol} / 1$ in DAN-, $\mathrm{P}<0.001$ ) (Fig. 1).

In order to assess the significance of examination of cough reflex sensitivity in diabetic patients, the correlation between CRS (C2 and C5 parameters) and selected HRV parameters was determined. A strong negative correlation between HRV and CRS parameters was found. These correlations were the strongest between $\mathrm{CVrr}$ and $\mathrm{C} 2(\mathrm{r}=-0.60)$ and $\mathrm{I} / \mathrm{E}$ and $\mathrm{C} 2(\mathrm{r}=$ -

Table 2. Comparison of CRS parameters between DAN+ and DAN-.

\begin{tabular}{|c|c|c|c|c|c|}
\hline & $\mathrm{D}$ & $(n=25)$ & & $n=32)$ & $\mathrm{P}$ \\
\hline & Median & IQR & Median & IQR & \\
\hline $\mathrm{C} 2$ & 625.0 & $68.4-625.0$ & 29.3 & $9.8-156.3$ & $<0.001$ \\
\hline C5 & 2500.0 & $1250.0-2500.0$ & 312.5 & $117.2-625.0$ & $<0.001$ \\
\hline
\end{tabular}



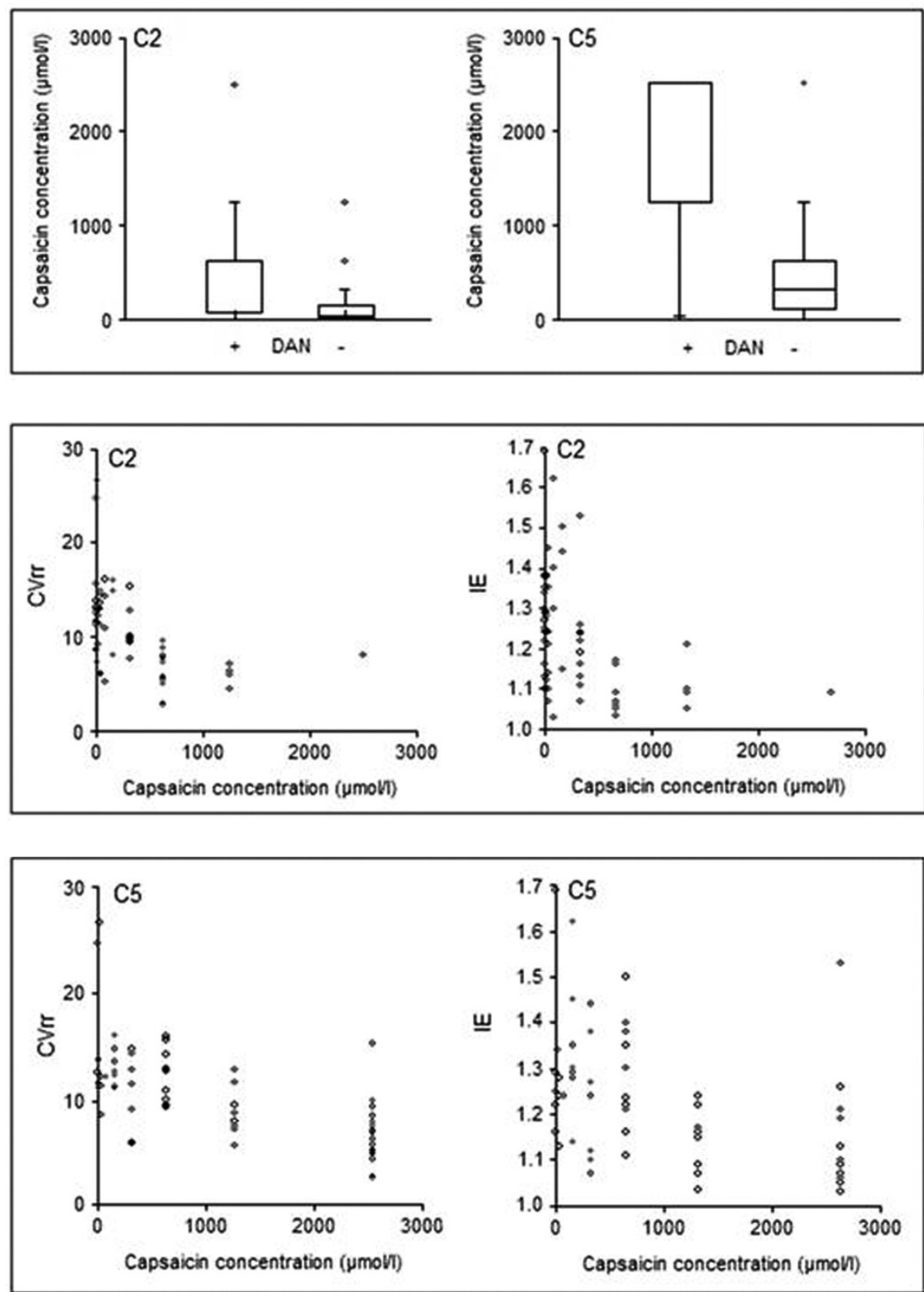

Fig. 1. Comparison of the C2 and C5 parameters describing cough reflex sensitivity between the patients with and without diabetic autonomic neuropathy (DAN+ and $\mathrm{DAN}-)(\mathrm{P}<0.001)$.

Fig. 2. Correlations between the CVrr and $\mathrm{I} / \mathrm{E}$ parameters of deep breathing test, describing heart rate variability, and $\mathrm{C} 2$, describing cough reflex sensitivity.

Fig. 3. Correlations between the CVrr and I/E parameters of deep breathing test, describing heart rate variability, and $\mathrm{C} 5$, describing cough reflex sensitivity.
0.55) (Fig. 2) as well as between CVrr and C5 ( $\mathrm{r}=-0.69)$ and between I/E and C5 (r=-0.68) (Fig. 3).

\section{Discussion}

The major finding of the present study was that the cough threshold for capsaicin was significantly enhanced in subjects with diabetic autonomic neuropathy. The DAN+ patients required a higher concentration of the tussigen to evoke cough compared with DAN-group (Fig. 1). Similar findings have been reported in other studies in which citric acid was used as a tussigen; 20 diabetic patients with diabetic neuropathy had enhanced cough threshold compared with 20 diabetic patients without neuropathy $[6,7]$. Consequently, a kind of vagal denervation has been suggested. In our previous work, we also found that a higher concentration of capsaicin is needed to evoke cough in 12 diabetic children with DAN compared with 23 children without DAN, although no difference was observed between the latter group and healthy children [8].

Another important finding of the present study was a strong negative correlation between cough reflex sensitivity, expressed by the concentration of capsaicin needed to evoke 2 and 5 coughs (C2 and C5 parameters, respectively) and heart rate variability, measured by parameters of deep breathing test (Fig. 2 and 3). Therefore, it is suggested that DAN influences respiratory system, especially the defense reflex mechanism. Our results are comparable with those of a previous study [8], where a correlation between $\mathrm{C} 2$ and E/I parameters was also observed. The main difference between the previous and present studies was in the method employed for cough reflex sensitivity. In the previous study, Provo Jet nebulizer (Ganshorn Medizin Electronik, Niederlauer, Germany) was used. The present study was performed by Koko Digi-Dos- 
er-Spirometer (nSpire Health Inc, Louisville, USA) which is regarded as a standardized method for CRS by the European Respiratory Society.

As outlined above, vagal denervation typically precedes sympathetic involvement in diabetes. A recent study shows that a fall in FEV1 (forced expiratory volume in one second), induced by the highest dose of methacholine, is significantly less in diabetic patients with cardiac autonomic neuropathy compared with diabetic patients without neuropathy and with healthy subjects [9]. These results suggest that diabetic autonomic neuropathy involves not only the efferent innervation of the heart, but also the afferent vagal innervation of the respiratory tract.

The present study demonstrates evidence for the influence of diabetic neuropathy on cough reflex threshold. However, diabetes also influences other functions of the respiratory system. In a prospective, multicenter study, the impact of cystic fibrosis-related diabetes mellitus on pulmonary function has been investigated [10]. FEV1 and FVC (forced vital capacity) significantly declined over a five year period in cystic fibrosis patients with DM, whereas cystic fibrosis patients without diabetes did not show a significant decrease during the study period. Sokolov et al. [11] examined 141 young patients (mean age 26 years) - 36 healthy subjects, 46 diabetic patients without complications, 48 diabetic patients with moderate complications, 34 with severe diabetic complications, and 13 with severe diabetic neuropathy and end-stage kidney disease. Compared with healthy subjects, there was a significantly lower lung diffusing capacity in diabetic subjects with moderate complications. Diabetic subjects with severe complications and end-stage kidney disease had, in addition, a lower total lung capacity. Similar findings have been noted in 16 patients with DM type 1 and 33 with DM type 2 in another study in which there also was a decreased concentration of the adhesion molecule E-selectin [12]. According to Pitocco et al. [13] a significant correlation exists between cardiac nervous system dysfunction (examined by HRV) and reduced lung diffusing capacity.

The examination of HRV is regarded as a main method for detection of diabetic autonomic neuropathy. Based on a strong negative correlation between cough reflex sensitivity and heart rate variability parameters found in the present study, we put forward a notion that examination of cough reflex sensitivity appears to be another suitable method for evaluating the diabetic autonomic neuropathy, even in its subclinical form.

Acknowledgments: Supported by Grant MZ SR 2006/38-UK05 and by Grant UK 44/2009. The study is performed in the Center of Experimental and Clinical Respirology.

Conflicts of interest: No conflicts of interest were declared by the authors in relation to this article.

\section{REFERENCES}

[1] Verrotti A, Loiacono G, Mohn A, Chiarelli F. New insights in diabetic autonomic neuropathy in children and adolescents. Eur J Endocrinol 2009; 4: [Epub ahead of print].

[2] Javorka M, Javorková J, Tonhajzerová I, Calkovská A, Javorka $\mathrm{K}$. Heart rate variability in young patients with diabetes mellitus and healthy subjects explored by Poincaré and sequence plots. Clin Physiol Funct Imaging 2005; 25(2): 119-27.

[3] Benbassat CA, Stern E, Kramer M, Lebzelter J, Blum I. Pulmonary function in patients with diabetes mellitus. Am J Med Sci 2001; 322: 127-32.

[4] Tonhajzerová I, Javorka K, Javorka M, Petrácková M. Cardiovascular autonomic nervous system tests: reference values in young people (15-19 years) and influence of age and gender. Clin Physiol Funct Imaging 2002; 22(6): 398403.

[5] Chang AB, Phelan PD, Roberts RGD, Robdertson CF. Capsaicin cough receptor sensitivity test in children. Eur Respir J 1996; 9: 2220-23

[6] Behera D, Das S, Dash RJ, Jindal SK. Cough reflex threshold in diabetes mellitus with and without autonomic neuropathy. Respiration 1995; 62: 263-68.

[7] Vianna LG, Gilbey SG, Barnes NC, Guy RJ, Gray BJ. Cough threshold to citric acid in diabetic patients with and without autonomic neuropathy. Thorax 1988; 43; 569-71.

[8] Varechová S, Durdík P, Cervenková V, Ciljaková M, Bánovcin P, Hanácek J. The influence of autonomic neuropathy on cough reflex sensitivity in children. J Physiol Pharmacol 2007; 58 Suppl 5: 705-15.

[9] Pieron M, Scheen AJ, Corhay JL, Radermecker MF, Lefebyre PJ. Bronchial reactivity in diabetic patients. Rev Mal Respir 1997; 14: 379-385.

[10] Rosenecker J, Hofler R, Steinkamp G, Eichler I, Smaczny C, Ballmann M, Posselt HG, Bargon J, von der Hardt H. Diabetes mellitus in patients with cystic fibrosis: the impact of diabetes mellitus on pulmonary function and clinical outcome. Eur J Med Res 2001; 6(8): 345-50.

[11] Sokolov EI, Demidov I. Gas exchange function of the lungs in patients with type 1 diabetes mellitus. Ter Arkh 2008; 80(3): 63-6.

[12] Boulbou MS, Gourgoulianis KI, Petinaki EA, Klisiaris VK, Maniatis AN, Molyvdas PA. Pulmonary function and circulating adhesions molecules in patients with diabetes mellitus. Can Respir J 2003; 10(5): 259-64.

[13] Pitocco D, Santangeli P, Fuso L, Zaccardi F, Longobardi A, Infusino F, Incalzi RA, Lanza GA, Crea F, Ghirlanda G. Association between reduced pulmonary diffusing capacity and cardiac autonomic dysfunction in Type 1 diabetes. Diabet Med 2008; 25(11): 1366-9.

Corresponding author:

Miriam Ciljaková, MD

Clinic of Children and Adolescents

Kollárova 2 St.

03601 Martin, Slovakia

Phone: +421434203254

Fax: +421434222678

E-mail: mciljakova@centrum.sk 